\title{
Como a Identidade de Uma São Paulo Cultural é Vendida: um estudo da agregação da identidade de São Paulo, SP, Brasil
}

\author{
Vitória Nonato Massinia \\ Alexandre Leonarde ${ }^{b}$
}

\begin{abstract}
Resumo
A identidade é instável e devido a isso pode mudar com diversos fatores como: sociedade, época, atores sociais, política e meios de comunicação. Antes São Paulo era a terra da garoa, e hoje a garoa se tornou mínima perto do que acontece na vida cosmopolita da cidade. Com isso, o objetivo da presente pesquisa é investigar se a identidade de São Paulo faz jus ao que ela oferece de entretenimento cultural. Por meio de uma pesquisa de gabinete, analisam-se as identidades da cidade ao longo dos anos, assim como, através de uma coleta de dados online, estuda-se como as agências e operadoras turísticas representam a capital nos seus sites, ou seja, para os turistas. Os resultados da coleta foram reproduzidos em duas imagens de nuvens de palavras, uma com os adjetivos da descrição de "Sampa", e outra com os atrativos mais indicados. Observou-se que o entretenimento na cidade já é destaque, sendo considerada a capital do entretenimento da América Latina.
\end{abstract}

Palavras-chave: Entretenimento cultural; Identidade; São Paulo; Turismo.

\section{Abstract \\ How the Identity of a Cultural São Paulo is Sold: a study of the aggregation of the identity of São Paulo}

Identity is unstable and due to that, it can change with several factors such as society, age, social actors, politics and the media. A few years ago, São Paulo was the land of drizzle, and today the drizzle is insignificant comparing to what is happening in the cosmopolitan life of the city. Therefore, the objective of the present research is to investigate the identity of São Paulo for what it has to offer in means of cultural entertainment. Through a cabinet survey, the identities of the city over the years were analyzed; online data about how agencies and tour operators represent a capital on their websites were also used. The results of the collection were reproduced in two word cloud images, one being the description of "Sampa", and the other one with the most indicated attractions. Noting that entertainment in the city is already at the spotlight, since São Paulo is the capital of entertainment at Latin America.

Keywords: Cultural entertainment; Identity; São Paulo; Tourism.

a. Bacharel em Turismo pela Escola de Comunicações e Artes da Universidade de São Paulo (ECAUSP). São Paulo, São Paulo, Brasil. E-mail: vitoria.massini@gmail.com

b. Pós-doutor em Estudos Culturais Pela Escola de Artes, Ciências e Humanidades da Universidade de São Paulo (EACH-USP). São Paulo, São Paulo, Brasil. Professor da Universidade São Judas Tadeu USJTE, São Paulo, São Paulo, Brasil.E-mail: aleonarde@uol.com.br 


\section{Resumen}

Como la Identidad Cultural de São Paulo es Vendida: un estudio agregado a la identidad de São Paulo

La identidad es inestable y puede cambiar su naturaleza debido a diversos factores tales como: sociedad, época, actores sociales, política y medios de comunicación. Antes São Paulo era la tierra de la "garoa" (una leve llovizna) y hoy en dia, año 2016, la garoa se ha vuelto mínima debido a variables de la Vida cosmopolita urbana. Con ello, el objetivo de la presente investigación es poner en manifiesto si la identidad de São Paulo corresponde con lo ella ofrece con respecto al entretenimiento cultural. Por medio de una encuesta de gabinete, se analizan las identidades de la ciudad a lo largo de los años, así como, a través de una recolección de datos online, se estudia cómo las agencias y operadoras turísticas representan la capital en sus sitios, o sea, para los turistas. Los resultados de la recolección fueron reproducidos en dos imágenes de nubes de palabras, una con los adjetivos de la descripción de "Sampa", y otra con los atractivos más indicados. Se observó que el entretenimento en la ciudad es importante y merece ser destacado, siendo la misma considerada la caporal del entretenimento de América Latina.

Palabras clave: Entretenimiento cultural; Identidad; San Pablo; Turismo.

\section{INTRODUÇÃO}

Este trabalho investiga como São Paulo é promovida por meio de agências e operadoras de viagens e turismo tanto da própria cidade como de outros locais, focando no segmento do entretenimento cultural, de modo a identificar se a cidade é considerada um destino cultural.

São Paulo é a quarta maior metrópole e a $14^{a}$ cidade mais globalizada do mundo, onde ocorrem 90 mil eventos anuais. Possui 15 mil restaurantes de 51 tipos de cozinha, 39 centros culturais, 125 museus, 164 teatros, 4 grandes casas de espetáculos e 280 salas de cinema (Observatório do Turismo, 2013, p. 138) Embora ofereça diversas opções de entretenimento para o visitante, São Paulo ainda é muito associada ao trabalho, fato que se reflete no turismo, uma vez que, em 2015, por exemplo, a cidade recebeu $45,1 \%$ de turistas estrangeiros vindos ao Brasil por motivos de negócios, eventos e convenções, e apenas 9,7\% por lazer (Brasil, 2016, p. 4).

As palavras-chaves que remetem a São Paulo, segundo Carvalho (2006), são "cultura", "vanguarda", "centro de tendências", "conhecimento" e "cidade-mundo". Contudo, Saliba (2004) mostra que termos como "trabalho", "tempo" e "progresso" também fazem parte da narrativa histórica da cidade, impossibilitando que ela seja reconhecida por uma única identidade.

A pesquisa tem o intuito de averiguar se atualmente há uma tendência de firmar o entretenimento como identidade cultural relevante em São Paulo. Para isso, foram buscados nas agências e operadoras de turismo e viagens os descritivos da cidade, a fim de verificar como ela é divulgada aos turistas.

A partir dessa busca, surge a hipótese de que a associação da cidade à cultura se encontra no imaginário do destino São Paulo. A relevância desta pesquisa está no levantamento de dados que podem comprovar que São Paulo já é vista como um local que oferece opções de diversão na área da cultura, apresentando-se como um produto do segmento do entretenimento cultural. 
Primeiramente utilizou-se a pesquisa de gabinete, aliada a uma posterior pesquisa online, através da ferramenta Google, por aproximadamente um mês, de 16 de agosto a 21 de setembro de 2016, na qual se buscou as agências e operadoras de viagens e/ou turismo do Brasil e do mundo que têm São Paulo entre seus destinos. Foram encontradas 32 empresas (dentre agências e operadoras), buscando-se identificar as palavras utilizadas para descrever o destino e os atrativos citados (dentro de roteiros ou como sugestão de passeio) que permitem associar a cidade ao segmento do entretenimento cultural. As maiores dificuldades da pesquisa se referem às limitações de idioma (não sendo possível analisar agências e operadoras cujo site não está disponível em espanhol, inglês, português ou italiano), à busca no navegador online (foram consultadas apenas agências e operadoras disponíveis na ferramenta do Google) e à credibilidade dos sites, pois não se sabe com certeza se algumas casas de turismo e viagens não têm como destino São Paulo, sendo possível que a viagem à cidade seja comercializada fora da web.

\section{IDENTIDADE}

definir identidade não é uma tarefa fácil, pois envolve características e crenças pessoais do sujeito ou da nação; por isso, seu estudo envolve áreas da psicologia e da sociologia. Castells (2008) apresenta a identidade como uma fonte de significado e experiências de um povo, construídas por atores sociais ou instituições dominantes. Em uma entrevista, Bauman (2005) alega que a identidade surge com as comunidades, por essas terem membros com diferentes ideias e, ao mesmo tempo, precisarem de um ideal em comum para que haja a sua união. A identidade é de escolha individual, mas há possibilidade de ser influenciada por terceiros. Para Gioielli (2005), essa identidade depende do contexto da vida e da ideologia que cerca o indivíduo, utilizando Freud, Lacan e Althusser para comprovar sua hipótese, já que esses autores apontam que a identidade e a personalidade não são autônomas, mas construídas em relação ao outro na dinâmica assumida com as estruturas e aparelhos ideológicos.

Conforme Castells (2008), as relações de poder marcam a construção social da identidade e, com isso, há três moldes que resultam na constituição da sociedade. São eles: a identidade legitimadora (as instituições dominantes da sociedade, almejando expandir e racionalizar sua dominação, e que se aplica nas teorias do nacionalismo), a identidade de resistência (levando à construção de comunidades de atores desvalorizados devido à dominação) e a identidade de projeto (com atores sociais redefinindo sua posição na sociedade e produzindo novas identidades por meio de material cultural).

Essa matéria é utilizada pela indústria cultural, que transforma a identidade em um estado de homogeneidade. Os produtos dessa indústria disseminam uma cultura artificial e descartável, sendo massificada com uma experiência alienada da identidade, ocorrendo essa crise devido à globalização e ao avanço capitalista, que interferem na construção identitária. Por isso, para compreender a identidade cultural do século XXI, fenômenos como globalização, novas tecnologias de comunicação e metafísica são essenciais (Gioielli, 2005). 
Com essa breve análise, percebe-se que não há somente uma definição para identidade, afinal ela é definida pelos significados do mundo que cerca o sujeito, logo variando conforme região, ano, instituições dominantes e outros fatores. Também por isso as diferentes influências de cada indivíduo e a identidade que ainda pode ser vista como um instrumento de unificação de uma nação tornam a identidade de grupos um tema delicado de discussão.

\section{Identidade da São Paulo antiga}

No imaginário popular, até pouco tempo a cidade de São Paulo não estaria no imaginário de turistas ou visitantes como um destino para o entretenimento, afinal as frases que mais a definiam eram: "terra da garoa", "cidade do trânsito", "cidade perigosa", "cidade para se fazer dinheiro", entre outras. Saliba (2004) apresenta uma linha do tempo com as múltiplas identidades paulistanas, representando as faces e fases da cidade: "bandeirante", que em 1938 se referia, conforme o dicionário Laudelino Freire, como natural de São Paulo, paulista; "romântica", com a segunda geração do romantismo (século XIX), exalando melancolia e vida noturna; "progresso", devido ao crescimento da cidade ao longo dos anos de 1870 até 1929; e "mobilidade", referindo-se à velocidade e ao desenvolvimento da cidade com seus meios de transportes - essa última identidade sendo utilizada devido à convicção na superioridade da cidade, projetada como centro dinâmico do progresso, do avanço de um Brasil atrasado. E, por último, o autor fala da identidade modernista do século XX, com os cronistas descrevendo São Paulo como um local desordenado e anárquico, enquanto os modernistas de 1922 apagavam essa visão com a Semana de Arte Moderna.

Depois da Semana de Arte Moderna e até 1945, D’Alessio (2008) afirma que houve rápida modernização, ocasionada pelo crescimento industrial. E após esse período a cidade nasce para as artes e produções culturais, com a criação do Museu de Arte de São Paulo Assis Chateaubriand (Masp) em 1947, do Museu de Arte Moderna de São Paulo (MAM) em 1948, e da Bienal Internacional, em 1951. Assim como nos anos 1950 e 1960 surgem diversos bares, galerias, cinemas e teatros, criando o ar cultural da metrópole. Pires (2001) também aponta o crescimento acelerado e desordenado, acrescentando que no começo do século XX surgem os parques para passeios, sociedades de fins recreativos, a instalação do cinema e a agitação da vida teatral.

O estudo de Bastos e Nova (2012) também oferece noções sobre a identidade da São Paulo de antigamente. As autoras estudaram dois guias de viagem, um de 1924 e outro de 1953, que apesar de apenas 29 anos de diferença entre eles, mostram uma cidade diferente, tendo em comum somente a função de um guia: orientar sobre as informações de locomoção, acomodação, alimentação e entretenimento.

O Guia ilustrado do viajante, de 1924, da editora Monteiro Lobato \& Cia, preocupou-se especialmente com a funcionalidade da cidade, e indica sua arquitetura como digna de visitação. Refere-se também aos imigrantes e sua grande quantidade (2,5 milhões) (Bastos \& Nova, 2012, p. 519), e dedica um capítulo aos monumentos, parques, jardins e ao entretenimento, com destaque para o Theatro Municipal, local onde poderiam ser contemplados os espetáculos internacionais. 0 guia também oferece dicas dos restaurantes, cafés, mercearias, feiras livres e 
mercados. Os museus, bibliotecas e instituições de ensino são mencionados no décimo capitulo. Logo, é um guia que serve tanto ao visitante como ao morador, contendo os serviços públicos e de entretenimento.

O segundo guia, da Melhoramentos, de 1953, é o Guia turístico da cidade de São Paulo e seus arredores. Publicado um ano antes do IV Centenário, ilustra os monumentos e locais de visitação de São Paulo, assim como cidades próximas e bairros não listados no primeiro guia, focando na história, densidade demográfica, dados geográficos, crescimento da população e edificações, enfatizando a metrópole São Paulo, mas abordando também o entretenimento, como locais de natureza e as cidades vizinhas balneárias e climáticas.

Tais estudos mostram que São Paulo muda sua identidade conforme a época que está vivendo. 0 progresso foi muito forte nas suas duas primeiras fases identitárias, permanecendo até o século XIX, mudando para uma identidade de boêmia graças ao movimento romântico. Contudo, a identidade de progresso volta no século XX com o uso da imagem do bandeirante, devido ao forte avanço que ocorria em São Paulo em meio a um Brasil estagnado. Outra mudança ocorre durante a famosa Semana de Arte Moderna de 1922, que acrescenta uma identidade cultural a São Paulo, como apresenta o guia de 1924, de uma cidade dinâmica com opções para o entretenimento. Todavia, essa identidade se intensifica no período do final da Segunda Guerra, no qual os grandes museus da cidade foram construídos, além de outras opções de entretenimento.

\section{Identidade da São Paulo atual}

Conforme Leonarde e Uvinha (2016), a nova identidade cultural associada ao entretenimento não é uma mudança exclusiva da economia, mas os autores também estabelecem a hipótese de que o entretenimento pertence à rotina dos seus moradores. A pesquisa Cultura SP: hábitos culturais dos paulistas (Leiva, 2014), realizada entre 11 de abril e 30 de maio de 2014, com quase 8 mil pessoas e em 21 cidades do estado de São Paulo, com a temática sobre a prática de atividades culturais e de lazer, demonstra que, na capital, $26 \%$ dos entrevistados realizam atividades culturais no tempo livre; dessas atividades, a primeira é o cinema (61\%), a segunda são festas populares (46\%) e a terceira são os shows (45\%); os locais mais frequentados são o Parque Ibirapuera (10\%) e o Masp (4\%).

A pesquisa mostra que, apesar de ser uma porcentagem pequena, ao menos uma parte da população de São Paulo já vive a realidade de ter, conhecer e usufruir do entretenimento na cidade. Isso é importante, pois o morador reconhece a sua cidade como um local com possibilidades para aproveitar o tempo livre, logo a teoria do turismo, de que um destino se consolida quando os moradores o percebem dessa maneira, já se estabelece em São Paulo. Carvalho (2006) demonstra que, em 2005, uma das dificuldades da capital em ter sua identidade como um produto turístico estava no fato que os paulistanos não a enxergavam como um destino, não entendendo seus diferenciais como atrativos turísticos. Hoje, mais de dez anos depois, conforme apontam Leonarde e Uvinha (2016), o entretenimento é significativo no cotidiano da cidade e para uma parte considerável de sua população, impactando a economia e sendo mais um elemento da identidade de São Paulo. 
Outra pesquisa que apresenta uma identidade de São Paulo é a de Mazzon e Vera (2008), realizada com foco nos turistas de negócios da cidade. Tal levantamento foi realizado em junho e julho de 2006 nos aeroportos de Guarulhos e Congonhas. Eles entrevistaram 622 pessoas, com o principal motivo de viagem sendo o turismo de negócios ou o turismo de negócios e lazer em conjunto. Em sua maioria, esses turistas eram do sexo masculino, com curso superior e gerentes de empresas, provindos da região Sul (nacional) e Argentina (internacional). Quando perguntados sobre qual a primeira ideia que lhes vem à mente quando se fala na cidade de São Paulo, as suas respostas foram:

1) Negócios/ Trabalho/ Novas oportunidade/ Ganhar dinheiro - 34,6\%;

2) Cidade grande/ Progresso/ Moderna - 13,7\%;

3) Trânsito/ Congestionamentos/ Transporte - 12,1\%;

4) Cultura/ Educação/ Bairros/ Paulista - 5,1\%;

5) Restaurantes/ Gastronomia - 3,2\%;

6) Compras/ Diversão/ Lazer - 2,6\%.

Nota-se que os turistas de negócios já identificam São Paulo com seu lado cultural, de entretenimento. Em sua pesquisa de 2004, com um total de 1.183 entrevistados em feiras de negócios da capital, Braga (2005) também estudou o perfil do turista de negócios e como utiliza seu tempo livre. Seus dados mostram que, apesar de muitos desses turistas terem tempo livre $(40,1 \%)$, eles o utilizam para descansar e dormir (33\%). Contudo, a maioria (56,8\%) conhece os atrativos turísticos de São Paulo, sendo os mais citados os histórico-culturais $(30,1 \%)$, os naturais $(27,8 \%)$ e os técnico-científicos $(12,3 \%)$. Tais atrativos são também os de maior interessante dos entrevistados: $53,5 \%$ mostraram curiosidade em conhecê-los, sendo a maioria os histórico-culturais $(31,6 \%)$, naturais $(14,9 \%)$, city tour $(14,7 \%)$ e shows/teatros/cinema $(11,1 \%)$. Em relação à identidade da capital, a grande maioria a vê como centro de negócios e serviços:

7) Cidade de negócios - 37,1\%;

8) Metrópole urbana - 20,2\%;

9) Diversas e modernas opções de entretenimento - 11\%;

10) Cultural e histórica - 10,8\%;

11) Gastronomia - 4,3\%.

Como conclusão de sua pesquisa, Braga (2005) considera que os turistas de negócios já entendem São Paulo também como uma cidade para aproveitar o tempo livre, e as atividades de maior interesse desse grupo são as artísticas $(20,2 \%)$. 
E, independentemente de a maior parte considerar São Paulo um local de negócios, a cidade oferece efervescência e diversas opções culturais e de entretenimento, almejadas no tempo livre.

D’Alessio (2008) também associa a identidade da cidade com negócios, mais especificamente como a capital de eventos, afinal em 2016 ocorreram 1.962 eventos, incluindo encontros, seminários e workshops, com mais de 16 milhões de visitantes (Observatório do Turismo, 2017, p. 16). 0 autor ainda acrescenta à capital os adjetivos "múltipla", "moderna" e "metrópole da diversidade brasileira".

\section{ENTRETENIMENTO E ENTRETENIMENTO CULTURAL}

\section{Entretenimento}

Para definir entretenimento, é preciso primeiramente analisar o lazer, que envolve as atividades que fazem oposição às obrigações da vida cotidiana, e por isso têm caráter de liberdade, prazer e livre vontade. 0 lazer pode ser dividido em três categorias: (1) função de descanso (como recuperação do cansaço); (2) função de desenvolvimento (possibilidades de novos conhecimentos); e (3) função de divertimento, recreação e entretenimento (fuga e evasão da rotina por meio de entretenimento, seja por atividades esportivas, jogos, viagens, cinema, teatro, leitura de romances etc.) (Dumazedier, 2000).

Apesar dessa terceira função do lazer ser um assunto recente na academia, o entretenimento existe há muito tempo, manifestado pelas feiras medievais, os circos de Roma, o teatro de rua, como na época de Shakespeare, as procissões e festas religiosas e outras manifestações populares ou de elite. Ele surge com as novas formações sociais (Trigo, 2003). Em seu livro, Trigo (2008) apresenta o entretenimento na percepção do setor turístico, como uma indústria ainda nova, conectada às novas possibilidades de tecnologia e buscando conquistar a sociedade.

Para a sociologia e a filosofia, com linhas críticas ao capitalismo liberal, o entretenimento é uma representação e uma simulação, visando à estabilidade dos sistemas dominantes pela alienação, gerando lucros a eles e, para as massas, formas pré-fabricadas de escapismo e diversão. Debord (2008) o interpreta como espetáculo, definido como uma atividade para as massas, sendo o resultado e o projeto do modo de produção existente, um modelo da vida dominante na sociedade e uma negação da vida real.

Trigo (2003) concorda que o entretenimento é uma atividade divertida, fácil, sensacional, irracional, previsível, utilizada como escape e geralmente paga. 0 autor, porém, apresenta o lado da importância do entretenimento relacionado à sociedade, à cultura e à economia, e também para as cidades, com cinemas, teatros, centros de musicais, lojas, locais esportivos e recreativos que atraem pessoas durante o tempo livre, tornando-se referências.

Hughes (2004, p. 73) afirma que o entretenimento é utilizado pelas cidades industriais que almejam ser reconhecidas como culturais, afinal elas não possuem o atrativo sol e praia. Logo, os visitantes irão procurá-las pelo seu entretenimento e patrimônio acessível, como nos casos de Roma e Paris, por exemplo. 
Leonarde e Uvinha (2016), em sua pesquisa da identidade cultural de São Paulo, indicaram que o crescimento do entretenimento na capital paulista foi o que levou a cidade a ser um atrativo turístico. Um turismo motivado pelos locais de entretenimento que a cidade possui, cujos turistas têm origem no próprio interior do estado e até em outros, pretendendo conhecer aquilo de que seus locais de origem carecem. Todos os autores da linha de pesquisa do entretenimento aqui citados apontam que este está muito conectado à Era Industrial e ao poder das mídias culturais.

\section{Entretenimento cultural}

Hughes (2004) analisa a arte associada ao entretenimento e afirma que ambos promovem a ampliação da mente e dos sentidos; contudo, a arte é relacionada à apreciação, e o entretenimento, ao escapismo. Juntos, englobam segmentos de turismo como: eventos esportivos, conferências, exposições e até mesmo economia. 0 turismo fornece uma oportunidade importante para organizações culturais e de patrimônio por atrair visitantes e aumentar as receitas. Sendo assim, contribui para o sucesso e o desenvolvimento.

Debord (2008) afirma que o espetáculo (entretenimento) é o momento em que a mercadoria ocupa totalmente a vida social, através do exagero da mídia, influenciando tudo o que é vivido. E quando a cultura se transforma nesse produto tem como objetivo ser a mercadoria principal dessa sociedade do entretenimento.

Já Trigo (2003) aponta que se divertir tem significado, seja por meio do esporte, da cultura, do turismo, da educação ou do entretenimento, sendo que esse último atrai consumo e oportunidades de negócios e, atualmente, o diferencial dos produtos e serviços são a informação, a diversão e as experiências. Essa mudança cultural ocorre durante a revolução industrial, no fluxo da pós-modernidade, mesma época em que surge o problema da homogeneização do entretenimento pelos meios de comunicação (detentores dos grandes grupos econômicos e da alta tecnologia global) e turismo de massa. Logo, a mídia reflete os objetivos desses grupos e não se preocupa que cultura seja complexa, padronizando-a.

Conforme Coelho (1989), foi com os primeiros jornais e romances de folhetim que surgiu a cultura de massa, tendo como características: não ser produzida por quem a consome; ser um produto do capital consumível; e os mais marcantes: a reificação e a alienação. Ele afirma que, quando a cultura de massa for relacionada aos aspectos negativos, deve-se então utilizar o termo cultura industrial.

Benhamou (2007) reflete que o produto cultural também tem caráter coletivo, por ser um consumo indivisível, ou seja, várias pessoas podem aproveitá-lo ao mesmo tempo, concluindo que a economia da cultura excluía as indústrias culturais por serem restritas ao campo das artes. Porém, a ligação dessa indústria com as artes é mais intensa do que se pensa, uma vez que gera uma economia da cultura por meio do cinema, livros e discos.

Pires (2001) coloca a importância da conexão entre lazer e cultura principalmente em museus, casas de cultura e núcleos históricos que muitas vezes não recebem bem os turistas, pois enxergam que cultura não é lazer. No entanto, essa atividade turística que envolve educação é muito importante, tanto para os visitantes que irão obter um saber ao final da visita como para esses locais culturais, 
visto que turistas geram lucros e divulgação dos locais, comprovando a importância de tal instituição dentro da comunidade e a razão pela qual deve continuar a existir e ser vista com respeito.

Percebe-se que existe o entretenimento com caráter alienador para as massas. Ainda assim, como aponta Pires (2001), há também uma forma de entretenimento voltado ao conhecimento e às experiências, que se encontra, por exemplo, nos museus. Sendo assim, é relevante o fato de que o atrativo mais visitado em 2014 na cidade de São Paulo tenha sido o Masp (Observatório do Turismo, 2014, p. 1), deduzindo-se que o entretenimento cultural em São Paulo explora a difusão de experiências e conhecimentos.

\section{A IDENTIDADE DE ENTRETENIMENTO CULTURAL EM SÃo PAULO}

\section{Divulgação feita pelas agências e operadoras}

0 estudo fez uso da pesquisa online, durante aproximadamente um mês, de 16 de agosto a 21 de setembro de 2016, com agências e operadoras de diferentes lugares do Brasil e do mundo que divulgam o destino São Paulo em seus sites. Cabe aqui ressaltar a relevância do fato da internet, em 2015, ter sido a principal fonte de consulta dos visitantes internacionais que estiveram no Brasil, totalizando um total de $44 \%$ dos turistas (Brasil, 2016). A pesquisa recolheu informações em sites nos idiomas português, inglês, espanhol e italiano (sites em outras línguas foram desconsiderados). Com as descobertas nota-se que grande parte mostra a cidade com seu lado de negócios e serviços, a metrópole da América Latina, mas que apesar disso tem muitos atrativos interessantes, uma cultura abundante e diversas opções de restaurantes e compras. Logo, mostram que apesar de ter fortes referências ligadas a serviços, negócios e economia, São Paulo é também o centro cultural do país.

É interessante perceber que a imigração também é muito citada na descrição da capital, e algumas identidades antigas ainda são utilizadas, como a "Locomotiva Brasileira" e "Terra da Garoa". Verificou-se também que o Norte e o Nordeste brasileiro vendem mais pacotes dos eventos da capital, especialmente shows; países europeus como Inglaterra e Irlanda apontam que São Paulo não tem as belezas naturais que se espera do Brasil, todavia há muito para se conhecer. Em cidades como Buenos Aires e Santiago do Chile, em suas operadoras e agências, os pacotes mais oferecidos para o Brasil são de destinos de praia e sol, pois são também grandes capitais latinas sem praias. Deduz-se que esses turistas procuram destinos diferentes do seu cotidiano, como as praias brasileiras.

Com esse levantamento foi feita uma análise por meio de nuvem das palavras mais utilizadas para descrever São Paulo (Figura 1) e os atrativos mais comentados (Figura 2). Conclui-se que, por meio dessas agências ou operadoras, São Paulo ainda tem uma identidade de negócios, centro financeiro, metrópole e, justamente por ser uma metrópole, oferece distintas opções de entretenimento, que já estão sendo usadas para divulgar uma São Paulo com cultura, gastronomia, parques, compras etc., que merece ser conhecida e experimentada. 
Figura 1 - Palavras mais utilizadas para descrever São Paulo

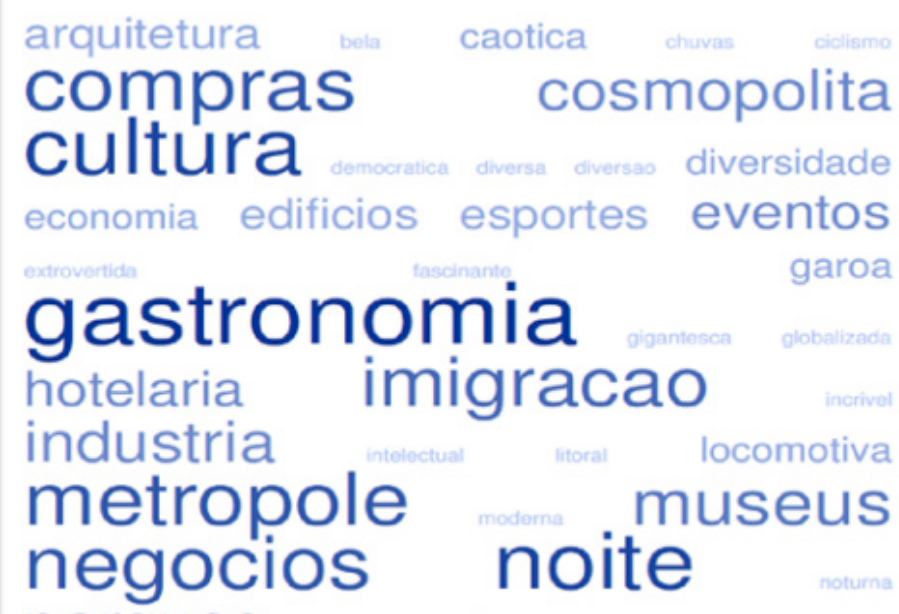
parques

populacao

Fonte - Elaborada pela autora

Figura 2 - Atrativos mais anunciados de São Paulo

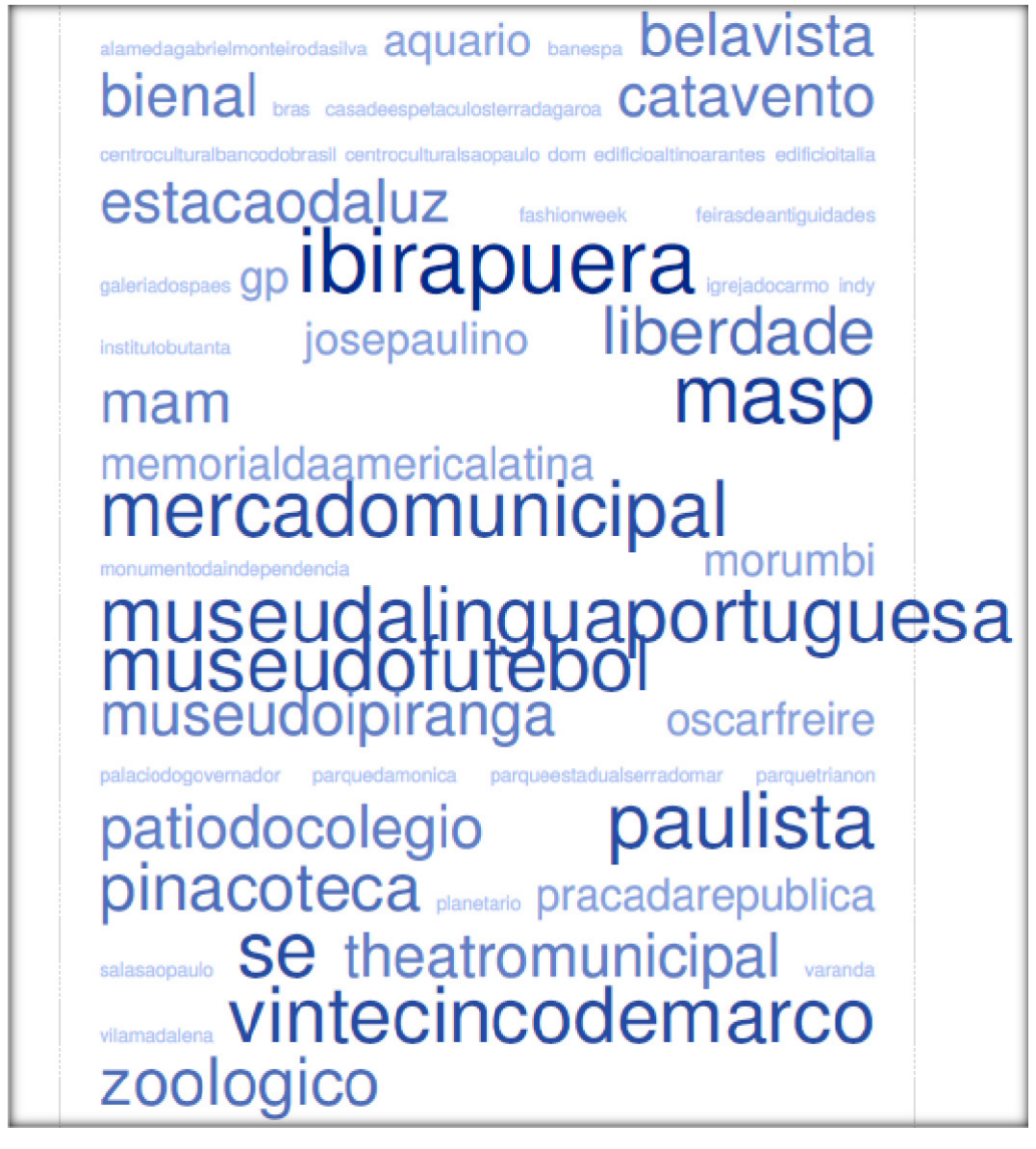

Fonte - Elaborada pela autora 


\section{Divulgação feita pelos órgãos de turismo}

A cidade de São Paulo tem três sites que auxiliam na promoção do destino. 0 site Cidade de São Paulo, administrado pela SPTuris (São Paulo Turismo), apresenta a capital como "Piratininga virou São Paulo: o colégio é hoje uma metrópole", narrando os principais fatos históricos que levaram São Paulo a ser o núcleo intelectual e centro econômico do país, além do crescente parque industrial que atraiu os imigrantes.

Desde 2011, o site utiliza como identidade a Marca São Paulo, que transmite a possibilidade de viver experiências únicas em São Paulo, afinal ela surpreende (o inesperado faz parte do cotidiano da metrópole).

Figura 3 - Marca São Paulo

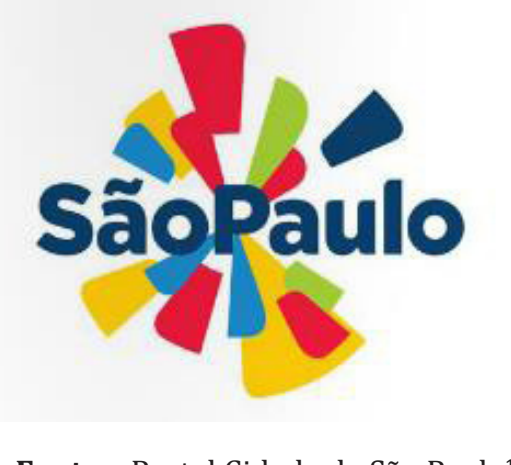

Fonte - Portal Cidade de São Paulo

O portal da SPTuris (São Paulo Turismo), empresa oficial de turismo e eventos da cidade, tem a missão de posicionar e promover a cidade como a capital dos negócios, conhecimento e entretenimento da América Latina, destacando seu caráter vanguardista e cultural. Menos voltado ao turista, o site foi desenvolvido a partir do antigo Cidade de São Paulo, chegando a direcionar o visitante para o portal em algumas informações sobre eventos e turismo. 0 logo do site traz o nome da capital seguido de "eventos, cultura, negócios" (Figura 4).

Figura 4 - Identidade SPTuris

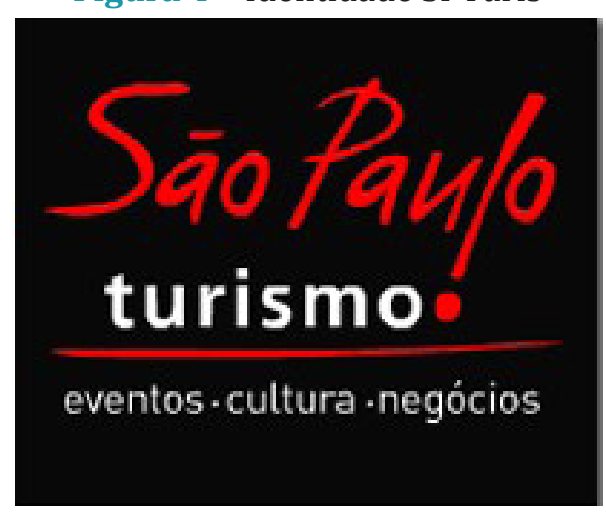

Fonte - Portal SPTuris ${ }^{2}$

1. Recuperado de http://www.cidadedesaopaulo.com em 1oo out. 2016.

2. Recuperado de http://www.spturis.com em 2 out. 2016. 
O São Paulo Convention \& Visitors Bureau (SPCVB) é uma entidade sem fins lucrativos, que busca ampliar o volume de negócios e o mercado de consumo na cidade, por meio da atividade turística, apoiando a melhoria dos serviços e atendimento aos visitantes. Seu site tem como título Visite São Paulo, ${ }^{3}$ e identifica a capital como bela, rica, intelectual, democrática, viva, esportiva, cultural, sentimental, romântica, moderna, séria, extrovertida, profissional. 0 portal conclui que é difícil escolher apenas um adjetivo para a metrópole cosmopolita, com diferentes raças, polo cultural e hoteleiro da América Latina, capital internacional de eventos, gastronomia, sede de grandes centros acadêmicos e diversas opções de entretenimento, com a campanha: "Venha a São Paulo, é tudo de bom!".

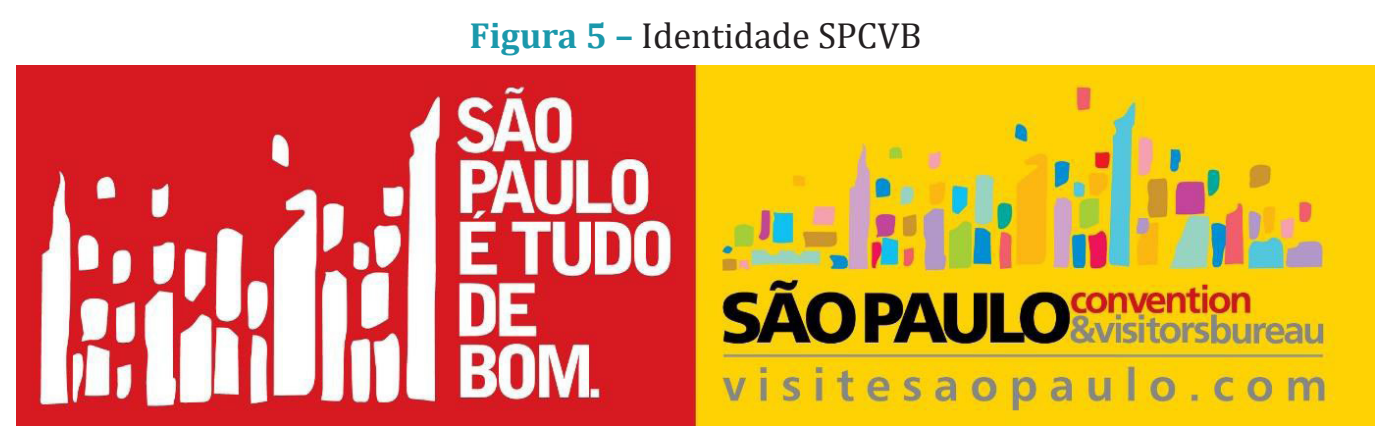

Fonte - Portal Visite São Paulo

0 portal Cidade de São Paulo mostra que, por ser uma metrópole e ter tido grande fluxo imigratório, há opções para todos os gostos, refletido nas suas múltiplas faces. É interessante notar que a identidade da SPTuris envolve três identidades de São Paulo (eventos, cultura e negócios) e que o órgão de turismo da capital já identificou a cultura como sua representação turística. O SPCVB também enfatiza as múltiplas identidades de São Paulo, uma cidade que oferece de tudo. Os sites oficiais de turismo de São Paulo identificam o entretenimento cultural como uma das múltiplas alternativas de lazer na cidade, sendo relevante notar que focalizam no leque de opções e características diferenciadas, únicas e múltiplas de que a cidade dispõe.

\section{CONSIDERAÇÕES FINAIS}

O estudo da identidade de São Paulo é um tema delicado, afinal envolve diferentes áreas de conhecimento e, com isso, opiniões que se confrontam. Para os antropólogos, o entretenimento é alienador. Já para os turismólogos, esse fenômeno, quando bem estruturado e executado, auxilia no suporte financeiro da instituição, além de promover cultura e novas formas de conhecimento.

A questão é delicada, pois, como foi estudado, a identidade está conectada ao significado, e este se refere aos atores sociais e instituições dominantes, isto é, a uma construção social, presente naquela sociedade e naquele momento, mudando conforme esses aspectos. E São Paulo, apesar de ter menos de 500 anos, já retratou diversos momentos, com sociedades que acompanharam essas mudanças.

3. Recuperado de http://www.visitesaopaulo.com em 2 out. 2016. 
A cidade passou pelo descobrimento de bandeirantes, um acelerado e intenso progresso, a vinda de imigrantes de diferentes partes, além da Semana de Arte Moderna, que direcionou a capital para as artes e a produção cultural. Em outras palavras, a identidade está relacionada ao que identifica a cidade, seu período e acontecimentos.

Atualmente, a metrópole ainda atua como polo de serviços e negócios do Brasil. Ainda assim, o paulistano realiza diversas atividades culturais e de lazer na cidade, como cinema, festas populares e shows, demonstrando que o entretenimento está presente na rotina dos moradores de São Paulo. E não somente para os habitantes da capital, mas para seu maior segmento de turistas: o de negócios, que já a conhecem e a percebem como um local cultural, com diversão e lazer. Alguns procuram e almejam conhecer os atrativos históricos e culturais da cidade, como expõem as pesquisas de Braga (2005) e Mazzon e Vera (2008). Então está no imaginário destes turistas, mesmo que visitem a cidade por motivos de negócios, a identidade do entretenimento, da cultura e da história de São Paulo.

Os órgãos oficiais de turismo da capital identificam essa oferta de entretenimento envolvendo experiências únicas e para todos os gostos de público e, por conta do caráter cosmopolita de São Paulo, acham difícil encontrar somente uma definição para ela. Também são destacados os eventos e negócios que movimentam o turismo local, apontando que a cidade é a capital cultural da América Latina.

Neste sentido, a hipótese de que em São Paulo a identidade de entretenimento cultural já está no imaginário da cidade é comprovada. Para maior credibilidade da afirmação, a presente pesquisa analisou agências e operadoras turísticas para saber como descreviam o destino São Paulo. Desse modo, percebeu-se que a gastronomia da cidade é muito divulgada por tais meios, e a cidade é promovida como o polo cultural da América Latina; e a vida noturna é também um dos aspectos mais usados para expressar a identidade de São Paulo. As identidades de negócios, metrópole, trânsito e até mesmo da garoa ainda estão presentes nesse levantamento, afinal São Paulo é uma capital de negócios, uma metrópole de trânsito intenso, mas também uma capital cultural.

Essa atual percepção de capital cultural já faz com que São Paulo seja uma referência de entretenimento e patrimônio, como mostram os dados numéricos da Fundação Instituto de Pesquisas Econômicas (Fipe) e do Ministério do Turismo, em que São Paulo foi o quarto destino mais visitado por motivo de lazer em 2015, o que demonstra que, embora a principal motivação para visitar São Paulo ainda sejam os negócios, eventos e convenções $(45,1 \%)$, o lazer $(9,7 \%)$ já apresenta números significativos (Brasil, 2016).

0 entretenimento deve ser usado para, além de divertir e relaxar, proporcionar conhecimento e auxiliar no crescimento e continuidade de instituições e locais que o promovem. Devido a isso, a escolha quanto ao tipo de entretenimento deve ser de vontade própria, e não imposta pela mídia da cultura de massa que, infelizmente, muitas vezes produz uma cultura que não ocasiona reflexão.

É importante a continuidade nos estudos da identidade de São Paulo no entretenimento para descobrir se, devido a seu caráter de referência cultural, ocorreu o aumento do fluxo de turistas, e se os visitantes têm mais acesso aos atrativos de entretenimento cultural, além de sua identidade de entretenimento se fortificar, sendo importante para a economia turística e o turismo de conhecimentos e experiências que a cidade tem o poder de proporcionar. 


\section{REFERÊNCIAS}

BASTOS, S., \& Nova, M. (2012). Guias de viagem e de turismo da Cidade de São Paulo (1924 e 1954): hospitalidade e patrimônio. Turismo em Análise, 23(3), 509-526. doi: 10.11606/issn.1984-4867.v23i3p509-526

BAUMAN, Z. (2005). Identidade: entrevista a Benedetto Vecchi (C. A. Medeiros, trad.). Rio de Janeiro: Jorge Zahar.

BENHAMOU, F. (2007) A economia da cultura (G. G. Souza, trad.). Cotia: Ateliê Editorial. BRAGA, D. C. (2005). À margem das feiras de negócios: uso do tempo livre do turista em São Paulo. Tese de Doutorado, Escola de Comunicações e Artes, Universidade de São Paulo, São Paulo.

BRASIL. Ministério do Turismo. (2016). Estudo da demanda turística internacional 2011-2015. Brasília: Ministério do Turismo.

CARVALHO, L. (2006). Desafios para consolidar um destino turístico: estudo preliminar do caso cidade de São Paulo. Turismo em Análise, 17(3), 24. doi: 10.11606/issn.19844867.v17i3p24-35

CASTELlS, M. (2008). O poder da identidade (6 $6^{\underline{a}}$ ed.). São Paulo: Paz e Terra. COELHO, T. (1989). O que é indústria cultural (13ạ ed.). São Paulo: Brasiliense.

D’ALESSIO, P. (2008). São Paulo cidade espetáculo: metrópole da diversidade brasileira. São Paulo: Dialeto.

DEBORD, G. (2008). A sociedade do espetáculo. Rio de Janeiro: Contraponto.

DUMAZEDIER, J. (2000). Lazer e cultura popular (3a ed.). São Paulo: Perspectiva.

GIOIELLI, R. (2005). A identidade líquida: a experiência identitária na contemporaneidade dinâmica. Dissertação de Mestrado, Escola de Comunicações e Artes, Universidade de São Paulo, São Paulo.

HUGHES, H. (2004). Artes, entretenimento e turismo (M. A. Carvalho, trad.). São Paulo: Roca.

LEIVA, J. (Org.). (2014). Cultura SP: hábitos culturais dos paulistas [Versão digital]. São Paulo: Tuva. Recuperado de http://www.pesquisasp.com.br/index.html

LEONARDE, A., \& Uvinha, R. R. (2016). A cidade do entretenimento: um estudo sobre a identidade cultural da cidade de São Paulo. Caderno Virtual de Turismo, 16(1), 32-45. doi: 10.18472/cvt.16n1.2016.0935

MAZZON, J., \& Vera, L. (2008). A opinião dos turistas de negócios sobre a imagem da cidade de São Paulo. Turismo em Análise, 19(3), 345-368. doi: 10.11606/issn.19844867.v19i3p345-368

OBSERVATÓRIO do Turismo (2013). São Paulo: capital internacional dos negócios. São Paulo: Observatório do Turismo.

OBSERVATÓRIO do Turismo (2014). Quem foi turista em 2014? São Paulo: Observatório do Turismo.

OBSERVATÓRIO do Turismo (2017). São Paulo: cidade do mundo 2017. São Paulo: Observatório do Turismo.

PIRES, M. J. (2001). Lazer e turismo cultural. São Paulo: Manole.

SALIBA, E. T. (2014). Histórias, memórias, tramas e dramas da identidade paulistana. In P. Porta, História da cidade de São Paulo: a cidade na primeira metade do século XX (1890-1954) (pp. 555-585). São Paulo: Paz e Terra. 
TRIGO, L. G. G. (2003). Entretenimento: uma análise cultural e econômica. Tese de LivreDocência, Escola de Comunicações e Artes, Universidade de São Paulo, São Paulo.

TRIGO, L. G. G. (2008). Entretenimento: uma crítica aberta. São Paulo: Senac.

Recebido em: $17 / 10 / 2017$

Aprovado em: 20/03/2018

\section{CONTRIBUIÇÕES}

Vitória Nonato Massini: definição do problema de pesquisa e objetivos; desenvolvimento da proposição teórica; realização da revisão bibliográfica e fundamentação teórica; coleta de dados; análise de dados; elaboração de tabelas, gráficos e figuras; revisão crítica do manuscrito; redação do manuscrito; adequação do manuscrito às normas da RTA.

Alexandre Leonarde: definição do problema de pesquisa e objetivos; desenvolvimento da proposição teórica; escolha dos procedimentos metodológicos; revisão crítica do manuscrito; adequação do manuscrito às normas da RTA. 